\title{
Characteristics of Postpartum Japanese Mothers Who Were Non- respondents to the Japan Environment and Children's Study
}

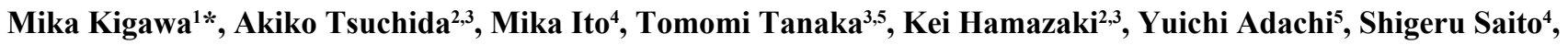 \\ Hidekuni Inadera ${ }^{2,3}$, The Japan Environment and Children's Study Group ${ }^{6}$ \\ ${ }^{I}$ Faculty of Health and Social Services, Kanagawa University of Human Services \\ ${ }^{2}$ Department of Public Health, Faculty of Medicine, Graduate School of Medicine and Pharmaceutical Sciences, University of Toyama \\ ${ }^{3}$ Toyama Regional Center for Japan Environment and Children's Study, University of Toyama \\ ${ }^{4}$ Department of Obstetrics \& Gynecology, Graduate School of Medicine and Pharmaceutical Sciences, University of Toyama \\ ${ }^{5}$ Department of Pediatrics and Developmental Medicine, Graduate School of Medicine and Pharmaceutical Sciences, University of Toyama \\ ${ }^{6}$ National Institute for Environmental Studies, Tsukuba city, Ibaraki, Japan
}

\begin{abstract}
Background: This study aimed to examine the factors behind survey non-response in mothers who had agreed to participate in a Japanese nationwide birth cohort study- The Japan Environment and Children's Study (JECS)- despite follow-ups. In this longitudinal cohort study, new mothers were asked to answer questionnaires one month after childbirth. Of 104,102 pregnant women who consented to participate, 96,860 were included in the study after excluding those with miscarriages, stillbirths or multiple births.
\end{abstract}

Method: Data from the self-administered questionnaires included participants' socioeconomic status, medical history, details regarding pregnancy and delivery, health status, and health-related behaviors. A JECS participation status for each participant's partner determined whether the partner provided an informed consent form and helped answer the survey. Multivariate logistic regression analysis was used to identify factors that could have potentially affected response/non-response to the survey.

Results:Survey non-response was related to the mother's age, socioeconomic status, health-related behavior, history of asthma, and psychological distress during pregnancy, as well as the child's health at birth. Additionally, active participation of partners in the JECS reduced the likelihood of non-response, and lack of partner participation significantly increased the likelihood of non-response.

Conclusion: The rate of survey response may be related to the level of the participants' interest and understanding of the study. In the future, approaches to the participant and others responsible for the care of the child should be considered to prevent non-response from ongoing surveys.

Keywords: Cohort study, Longitudinal study, Survey response, Survey non-response, Population characteristics, Regression analysis

\section{Introduction}

The Japan Environment and Children's Study (JECS) is a nationwide birth cohort study that began in 2011. The JECS collects data from the gestation period until the child is 13 years old and aims to examine environmental factors related to children's health. Over three years, beginning in 2011, approximately 100,000 pregnant women were recruited to take part in the study. Data were collected via biological and environmental samples as well as survey questionnaires [1]. As of this writing, the data from the samples are available from one month after the child is born [2].

One of the issues when using survey questionnaires is non-response. Response rates for survey research in Japan have seen a decreasing trend, with even surveys conducted by national or local governments receiving only a $70 \%$ response rate [3]. This may affect the quality of data, since the statistical power could be affected if the number of data points were less than called for by the study design. More importantly, selection bias may be introduced if non-response is related to certain participant characteristics. In health-related survey research, previous studies have shown that survey responses are affected by participant interest and their understanding of the health problems being studied and relevant health behaviors [4-10]. As a result, in survey research, it is necessary to examine the characteristics of the sample from whom responses could not be obtained.

*Correspondence to: Mika Kigawa, Faculty of Health and Social Services, Kanagawa University of Human Services, Japan, Tel: +81-46-828-2752, E-mail:kigawac5s@kuhs.ac.jp

Citation: Kigawa M, Tsuchida A, Ito M, Tanaka T, Hamazaki K, et al. (2020) Characteristics of Postpartum Japanese Mothers Who Were Non-respondents to the Japan Environment and Children's Study. J Pediatr Congenit Dis 6(1): 105. DOI: https://doi.org/10.47275/2379-6707-105.

Received: July 05, 2020; Accepted: August 08, 2020; Published: August 12, 2020

Copyright: $\odot 2020$ Kigawa M, et al. This is an Open Access article distributed under the terms of the Creative Commons Attribution 4.0 International License (CCBY) (http://creativecommons.org/licenses/by/4.0/) which permits commercial use, including reproduction, adaptation, and distribution of the article provided the original author and source are credited. 


\section{Materials and Methods}

\section{JECS Study design}

The JECS uses self-administered survey questionnaires to collect data about health status and other socioeconomic factors. This research examined two separate baseline surveys, the first conducted during early pregnancy (MT-1)- when pregnant women were recruited- and the second during mid-to-late pregnancy (MT-2). These questionnaires were delivered to women who were enrolled in the JECS and were collected either by the study's Research Coordinators in the obstetrics departments or by mail. At the time of recruitment, partners of the women who consented to participate were also asked to take part. Those who agreed were asked to complete a self-administered questionnaire (FT-1). Delivery and return of the FT-1 took place either directly with the study's Research Coordinators at a participating medical facility or via mail. Medical data of the mothers' pregnancies and deliveries as well as of their children (the population of interest of the JECS), were transcribed by physicians, midwives, nurses, and/or Research Coordinators from the facilities' medical records (Dr-0m). A self-administered survey was provided by the Research Coordinators, who collected responses from participating mothers personally or by mail. The survey was to be completed and returned one month after the child's birth.

\section{Current study design}

The present study was based on two datasets that were distributed only among interested researchers from June 2016 to October 2016 . These datasets are scheduled to be made publicly available in the future, but using them will require approval from the research group. The datasets consisted of information on 104,102 fetuses, including cases of miscarriages and stillbirths. Of these, the analysis used data from 96,860 participating mothers. Data from mothers who had joined the study more than once during the study's recruiting period (due to multiple pregnancies) and who withdrew from the study were eliminated. We classified mothers into two groups: respondents, who returned the questionnaire one month after the child's birth, and non-respondents, who did not return it. For analysis, we examined marital status, cohabitation, level of education, household income, medical history, health-related behaviors, and the number of hours worked per week. For health-related quality of life (HRQOL), the data used were from the Japanese version of the Short Form-8 Health Survey (SF-8) [11]. Data on psychological distress were from the Japanese version of the Kessler Psychological Distress Scale (K6) [12]. Data regarding delivery and neonatal health (age of gestation at birth, Apgar scores, physical anomalies, duration of hospital stay, and referral for specialized care) were obtained from medical records.

The mothers' ages at delivery were divided into four categories: under 25 years, 25-29 years, 30-34 years and 35 years and older. As for partner participation in the JECS, we created three categories according to whether a consent form and/or a completed survey questionnaire were received during the mother's pregnancy. The categories were as follows: non-participant (no consent form), inactive participant (agreed to participate in the study but delayed their response or did not return a completed survey), and active participants (agreed to participate and returned a completed survey). The gestational age of the children at birth was divided into three categories: less than 34 weeks, 34-36 weeks, and 37 weeks and more. For the Apgar score, seven was the cutoff point. Two groups appeared: those scoring above and below seven. The cutoff point for the duration of hospital stay for neonates was eight days; the two groups created were those who stayed in the hospital for fewer than eight days and those who stayed for eight days or more. Psychological distress was identified in those whose K6 score was greater than or equal to 13. Two levels of education were identified: those with less than 13 years and those with 13 or more years of schooling. Three household income levels were created: less than $¥ 4$ million, $¥ 4$ million to $¥ 12$ million, and more than $¥ 12$ million. Finally, for hours worked per week during pregnancy, responses were grouped into three categories: not working, working fewer than 40 hours/week (the $50^{\text {th }}$ percentile calculated after excluding 'not working' participants), and working 40 or more hours per week.

\section{Ethical considerations}

The JECS protocol was reviewed and approved by the Ministry of Environment's Institutional Review Board on Epidemiological Studies and the ethics committees of all participating institutions. Written informed consent was obtained from all participants.

\section{Analysis}

Pearson's chi-squared and Fisher's exact tests were used to examine the differences in the characteristic of responders and non-responders in the survey as well as the participants' partners' survey participation categories. Binary logistic regression was then performed using the variables found to have a significant relationship with survey response to obtain odds ratios with a confidence interval (CI) of 95\%. Additional analysis was performed to confirm the results using multivariate singular value decomposition to impute missing data. For the imputation of missing data, the method of singular value decomposition complement was used. This study used two-tailed tests with a significance level of 0.01 . JMP ${ }^{\circledR}$ Pro version 11 (SAS Institute Inc., Cary, NC, USA) was used for the analyses.

\section{Results}

\section{Participant characteristics}

The response rate for the survey at one month after birth was $95.4 \%(92,464 / 96,860)$. Table 1 shows the participant characteristics from the baseline surveys. The participants who belonged to the responder group tended to be older than those who were part of the non-responder group. With regard to medical history, more non-responders had a history of bronchial asthma, depression, dysautonomia or anxiety disorder, while responders tended to have a history of allergic rhinitis, allergic conjunctivitis, or myopia. Based on the K6 scores, more women in the nonresponder group were suspected to experience psychological distress during pregnancy. More women in the non-responder group had multiple 
Citation: Kigawa M, Tsuchida A, Ito M, Tanaka T, Hamazaki K, et al. (2020) Characteristics of Postpartum Japanese Mothers Who Were Non-respondents to the Japan

Table 1. Characteristics of the sample.

\begin{tabular}{|c|c|c|c|}
\hline & $\begin{array}{c}\text { Responder } \\
(n=92,464)\end{array}$ & $\begin{array}{l}\text { Non-responder } \\
\quad(n=4,396)\end{array}$ & \\
\hline & $\%$ & $\%$ & p-value \\
\hline \multicolumn{4}{|l|}{ Participants characteristics } \\
\hline Age at delivery $(n=94,911)$ & $(n=92,458)$ & $(n=2,453)$ & $<0.001$ \\
\hline Less than 25 & 9.7 & 21.4 & \\
\hline $25-29$ & 27.5 & 26.6 & \\
\hline $30-34$ & 35.4 & 29.2 & \\
\hline 35 and over & 27.4 & 22.8 & \\
\hline Medical history $(n=94,347)$ & $(n=91,811)$ & $(n=2,536)$ & \\
\hline Bronchial asthma & 10.8 & 12.9 & 0.001 \\
\hline Allergic rhinitis & 36.1 & 32.4 & $<0.001$ \\
\hline Allergic conjunctivitis & 9.9 & 8.0 & $<0.001$ \\
\hline Depression & 3.0 & 4.6 & $<0.001$ \\
\hline Dysautonomia & 3.6 & 5.4 & $<0.001$ \\
\hline Anxiety disorder & 2.8 & 4.2 & $<0.001$ \\
\hline Myopia & 33.2 & 27.2 & $<0.001$ \\
\hline \multicolumn{3}{|l|}{ Self-Administered mental health (K6) during pregnancy } & $<0.001$ \\
\hline Less than 13 points & 96.5 & 94.4 & \\
\hline 13 points and over & 3.5 & 5.6 & \\
\hline Multiple birth & 2.4 & 1.8 & 0.006 \\
\hline \multicolumn{4}{|l|}{ Problems at delivery } \\
\hline \multirow{2}{*}{ Abnormality of placenta/umbilical cord $(n=91,664)$} & $(n=89,506)$ & $(n=2,158)$ & $<0.001$ \\
\hline & 23.0 & 26.2 & \\
\hline \multirow[t]{2}{*}{ Neonatal jaundice $(n=91,758)$} & $(n=89,667)$ & $(n=2,081)$ & $<0.001$ \\
\hline & 14.6 & 20.7 & \\
\hline \multirow{3}{*}{$\begin{array}{l}\text { Neonatal referrals for specialized care }(n=91,998) \\
\text { Pregnancy complications }(n=92,826)\end{array}$} & 6.1 & 20.0 & $<0.001$ \\
\hline & $(n=90,581)$ & $(n=2,245)$ & $<0.001$ \\
\hline & 15.1 & 18.6 & \\
\hline \multirow[t]{2}{*}{ Obstetric complications $(n=92,924)$} & $(n=90,667)$ & $(n=2,257)$ & $<0.001$ \\
\hline & 46.8 & 54.1 & \\
\hline Neonatal physical anomalies & 6.6 & 13.9 & $<0.001$ \\
\hline Apgar Index at 1 minute (less than 7) & 2.2 & 21.0 & $<0.001$ \\
\hline The gestational age of the children at birth $(n=92,796)$ & $(n=90,563)$ & $(n=2,233)$ & $<0.001$ \\
\hline Less than 34 weeks & 0.8 & 7.7 & \\
\hline $34-37$ weeks & 3.6 & 7.0 & \\
\hline 37 weeks and more & 95.6 & 85.3 & \\
\hline Date of hospitalization (Child) $(n=88,649)$ & $(n=86,739)$ & $(n=1,910)$ & $<0.001$ \\
\hline Less than 8 days & 79.9 & 69.9 & \\
\hline 8 days and more & 20.1 & 30.1 & \\
\hline \multicolumn{4}{|l|}{ Health-related behavior and environment } \\
\hline Smoking habits during early pregnancy $(n=93,637)$ & $(n=91,153)$ & $(n=2,484)$ & $<0.001$ \\
\hline Never smoked & 58.5 & 49.8 & \\
\hline Smokers who quit before pregnancy & 23.4 & 21.9 & \\
\hline Smokers who quit after pregnancy & 13.5 & 17.7 & \\
\hline Smoker & 4.6 & 10.6 & \\
\hline \multirow[t]{2}{*}{ Some family members smokes in same room ${ }^{\text {a }}(n=93,517)$} & $(n=91,023)$ & $(n=2,494)$ & $<0.001$ \\
\hline & 53.4 & 60.0 & \\
\hline \multirow[t]{2}{*}{ Exposed weekly to secondary smoke before pregnancy ${ }^{\mathrm{b}}(n=93,880)$} & $(n=91,375)$ & $(n=2,505)$ & $<0.001$ \\
\hline & 18.2 & 25.2 & \\
\hline Smoking habits during pregnancy $(n=92,541)$ & $(n=90,933)$ & $(n=1,608)$ & $<0.001$ \\
\hline Never smoked & 58.1 & 46.9 & \\
\hline Smokers who quit before pregnancy & 23.6 & 20.7 & \\
\hline Smokers who quit after pregnancy & 13.9 & 20.1 & \\
\hline Smoker & 4.4 & 12.3 & \\
\hline Alcohol consumption during early pregnancy $(n=93,897)$ & $(n=91,407)$ & $(n=2,490)$ & 0.001 \\
\hline Never drink & 33.4 & 34.6 & \\
\hline Drinkers who quit before pregnancy & 55.5 & 57.5 & \\
\hline Drinkers & 10.1 & 7.9 & \\
\hline \multicolumn{4}{|l|}{ Socioeconomic status } \\
\hline Education $(n=92,769)$ & $(n=91,165)$ & $(n=1,604)$ & $<0.001$ \\
\hline
\end{tabular}


Citation: Kigawa M, Tsuchida A, Ito M, Tanaka T, Hamazaki K, et al. (2020) Characteristics of Postpartum Japanese Mothers Who Were Non-respondents to the Japan Environment and Children's Study. J Pediatr Congenit Dis 6(1): 105. DOI: https://doi.org/10.47275/2379-6707-105.

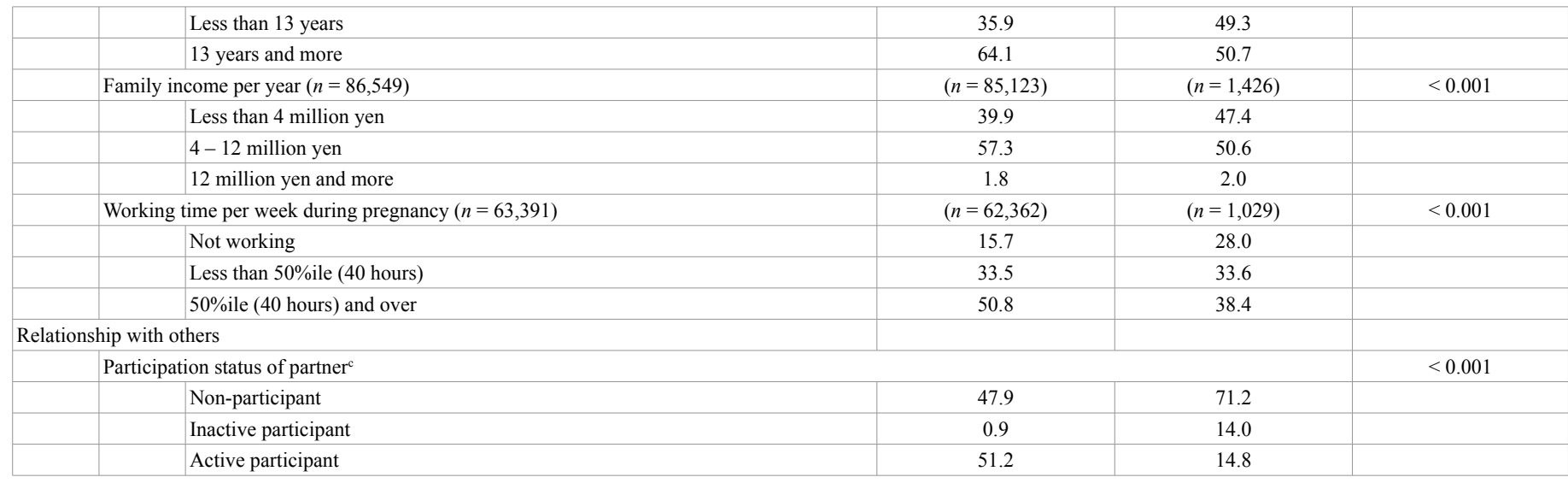

"Fisher's exact test, a- "Somebody" is defined as subjects having family members who smoke in the same room. b- "Weekly" is defined as subjects exposed at least once a week.c- Passive participation of a partner refers to those who agreed to participate but did not respond to the questionnaire. Active participation of a partner refers to those who answered the questionnaire.

births than those in the responder group. Based on the SF-8 scores, HRQOL was not significantly different between the non-responder group and responder group.

Significantly more women in the non-responder group had placental or umbilical cord abnormalities and other complications. As for neonatal health, significantly more neonates of non-responders had jaundice, physical anomalies or were referred for specialized care. Additionally, more neonates in the non-responder group versus the responder group had one-minute Apgar scores of less than seven. Significantly more neonates from the non-responder group stayed in the hospital for eight or more days and were referred for specialized care. Babies born to the nonresponder group were born at significantly earlier gestational age.

Regarding health-related behaviors, more women in the non-responder group smoked during the early or entire pregnancy period. Furthermore, significantly more women in the non-responder group were often exposed to secondhand smoke before pregnancy. There was no significant difference in alcohol consumption during pregnancy between the response groups.

With regard to socioeconomic factors, more women in the non-responder group had fewer than 13 years of schooling and less than $¥ 4$ million in the household income. The non-responder and responder groups differed in terms of working hours. In the non-responder group, significantly fewer women worked for 40 hours or more per week during pregnancy and some did not work at all.

As for partner participation in the study, significantly more partners of responders took part actively.

\section{Factors related to survey non-response}

Variables that were significantly related to survey response/non-response were analyzed using binary logistic regression. Table 2 shows the likelihood of non-response to the JECS survey, represented by odds ratios and 95\% confidence intervals. The factor that most strongly predicted survey non-response was partner participation status. When compared to participants whose partners did not take part in the JECS at all, the odds of survey non-response were $0.44(0.36,0.52)$ and $6.92(4.87,9.84)$ when the partners were active participants and inactive participants respectively. Finally, for neonatal health factors, the non-response odds ratios among participants whose children had low one-minute Apgar scores, had referral for specialised care, or had physical anomalies were significantly greater than 1 (2.64, 2.33, and 2.35, respectively).

Table 2: Multivariate Logistic Regression Predicting the probability of Survey Non-response.

\begin{tabular}{|c|c|c|c|c|}
\hline \multirow[t]{3}{*}{ Variable } & \multirow{2}{*}{\multicolumn{2}{|c|}{$\begin{array}{c}\text { Model 1 } \\
\text { AICc }=6124.14\end{array}$}} & \multirow{2}{*}{\multicolumn{2}{|c|}{$\begin{array}{c}\text { Model 2 } \\
\text { AICc }=16761.5\end{array}$}} \\
\hline & & & & \\
\hline & OR $(95 \% \mathrm{CI})$ & p-value & OR $(95 \% \mathrm{CI})$ & p-value \\
\hline \multicolumn{5}{|l|}{ Age at delivery } \\
\hline Less than 25 & Reference & & Reference & \\
\hline $25-29$ & $0.58(0.45,0.74)$ & $<0.001$ & $0.63(0.54,0.72)$ & $<0.001$ \\
\hline $30-34$ & $0.46(0.36,0.60)$ & $<0.001$ & $0.59(0.51,0.68)$ & $<0.001$ \\
\hline More than 35 & $0.44(0.33,0.57)$ & $<0.001$ & $0.59(0.51,0.69)$ & $<0.001$ \\
\hline Medical history of bronchial asthma (have/have not) & $1.30(1.04,1.63)$ & 0.023 & $2.81(2.54,3.11)$ & $<0.001$ \\
\hline $\begin{array}{l}\text { K6 during pregnancy } \\
\text { (13 and over/less than 13) }\end{array}$ & $1.51(1.08,2.11)$ & 0.016 & $5.26(4.67,5.92)$ & $<0.001$ \\
\hline Multiple births (Yes/ No) & $1.21(0.80,1.83)$ & 0.362 & $1.44(1.13,1.84)$ & 0.003 \\
\hline Neonatal referral at delivery (have/have not) & $2.33(1.82,2.99)$ & $<0.001$ & $2.02(1.74,2.34)$ & $<0.001$ \\
\hline Neonatal physical anomalies (have/have not) & $2.35(1.89,2.92)$ & $<0.001$ & $1.70(1.47,1.95)$ & $<0.001$ \\
\hline Apgar Index at $1 \mathrm{~min}$ (less than 7/7 and more) & $2.64(1.96,3.56)$ & $<0.001$ & $3.70(3.12,4.39)$ & $<0.001$ \\
\hline The gestational age of the children at birth & & & & \\
\hline
\end{tabular}


Citation: Kigawa M, Tsuchida A, Ito M, Tanaka T, Hamazaki K, et al. (2020) Characteristics of Postpartum Japanese Mothers Who Were Non-respondents to the Japan Environment and Children's Study. J Pediatr Congenit Dis 6(1): 105. DOI: https://doi.org/10.47275/2379-6707-105.

\begin{tabular}{|c|c|c|c|c|}
\hline $37 \mathrm{w}$ and More & Reference & & Reference & \\
\hline $34-36 w$ & $1.65(1.22,2.23)$ & 0.001 & $1.41(1.18,1.69)$ & $<0.001$ \\
\hline $22-33 w$ & $2.82(1.92,4.13)$ & $<0.001$ & $2.32(1.85,2.92)$ & $<0.001$ \\
\hline \multicolumn{5}{|l|}{ Smoking habits during pregnancy } \\
\hline Never smoked & Reference & & Reference & \\
\hline Smokers who quit before pregnancy & $1.17(0.94,1.46)$ & 0.147 & $1.46(1.31,1.63)$ & $<0.001$ \\
\hline Smokers who quit after pregnancy & $1.50(1.20,1.87)$ & $<0.001$ & $1.13(0.99,1.30)$ & 0.076 \\
\hline Smoker & $2.74(2.09,3.57)$ & $<0.001$ & $1.73(1.45,20.6)$ & $<0.001$ \\
\hline \multicolumn{5}{|l|}{ Alcohol consumption during pregnancy } \\
\hline Never drink & Reference & & Reference & \\
\hline Drinkers who quit before pregnancy & $0.95(0.79,1.13)$ & 0.544 & $0.94(0.85,1.03)$ & 0.200 \\
\hline Drinkers & $0.66(0.47,0.92)$ & 0.014 & $0.62(0.51,0.75)$ & $<0.001$ \\
\hline $\begin{array}{l}\text { Education status } \\
\quad(13 \text { and over/less than } 13)\end{array}$ & $0.78(0.65,0.93)$ & 0.007 & $0.78(0.70,0.87)$ & $<0.001$ \\
\hline \multicolumn{5}{|l|}{ Family income per year } \\
\hline Less than 4 million yen & Reference & & Reference & \\
\hline $4-12$ million yen & $0.98(0.82,1.17)$ & 0.843 & $1.26(1.13,1.39)$ & $<0.001$ \\
\hline 12 million yen and more & $1.19(0.65,2.16)$ & 0.572 & $0.80(0.72,0.88)$ & $<0.001$ \\
\hline \multicolumn{5}{|l|}{ Working time during pregnancy } \\
\hline Not working & Reference & & Reference & \\
\hline Less than 40 hours/week & $0.69(0.56,0.85)$ & $<0.001$ & $1.28(1.12,1.46)$ & $<0.001$ \\
\hline 40 hours/week and over & $0.58(0.47,0.71)$ & $<0.001$ & $0.52(0.44,0.62)$ & $<0.001$ \\
\hline \multicolumn{5}{|c|}{ Participation status of participants' partners } \\
\hline Non-participation & Reference & & Reference & \\
\hline Inactive participation & $6.92(4.87,9.84)$ & $<0.001$ & $9.92(8.46,11.6)$ & $<0.001$ \\
\hline Active participation & $0.44(0.36,0.52)$ & $<0.001$ & $0.36(0.32,0.40)$ & $<0.001$ \\
\hline
\end{tabular}

Model 1: Crude data. Model 2: Model 1 with multivariate singular value decomposition to impute missing values. AIC: Akaike's Information Criterion

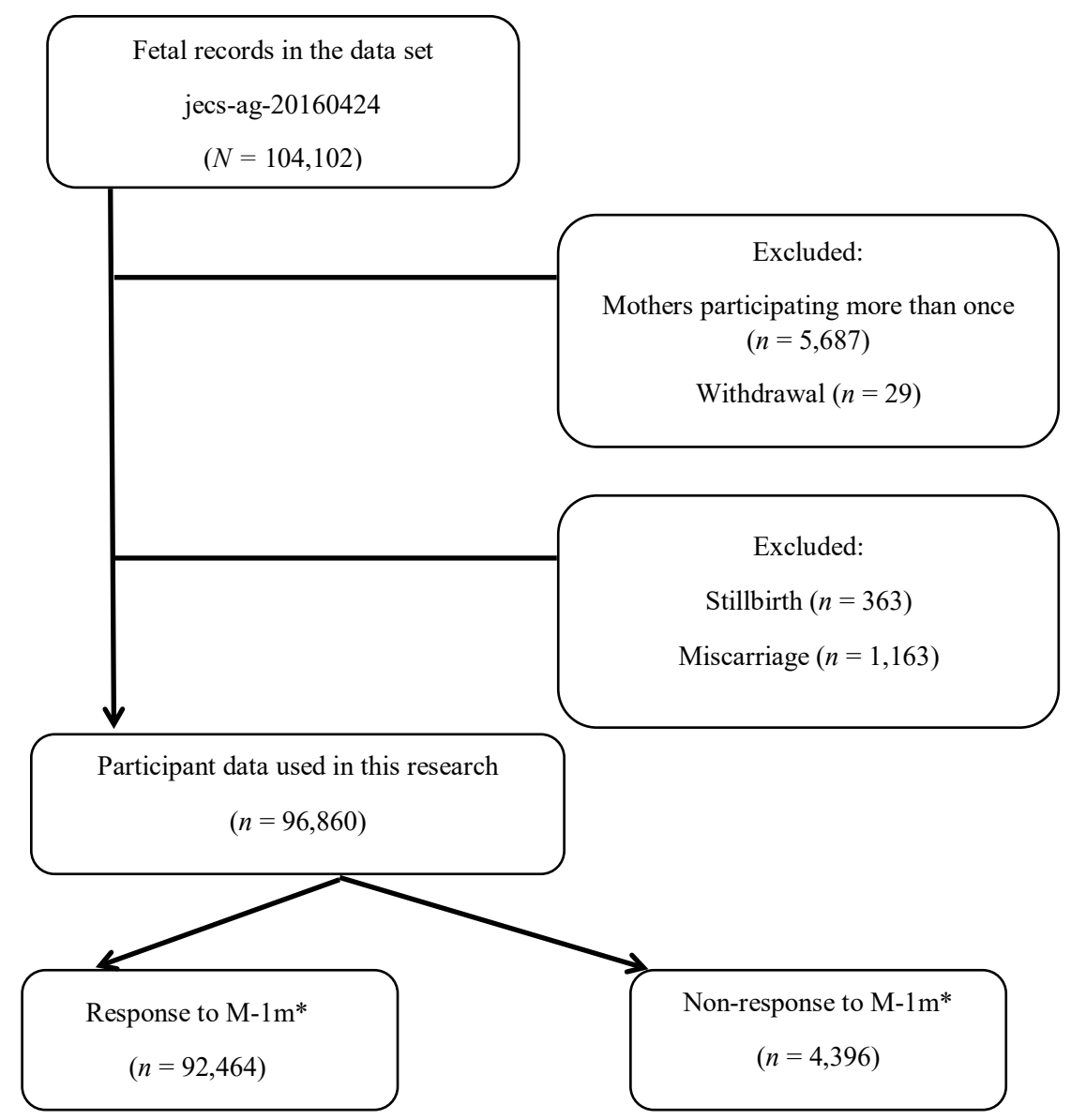

Figure 1: Inclusion of participants. "M-1m: the questionnaire sheet given one month after birth. 
In this study, multivariate singular value decomposition was used to impute missing data. Logistic regression was then used to examine how each factor related to survey non-response. The resulting odds ratios showed similar trends. The odds of non-response were decreased for those who had long working hours during pregnancy, actively participating partners, and transcriptions of multiple prenatal examinations. Conversely, the odds of non-response were significantly increased for those with a history of bronchial asthma, a high score of K6, and a low one-minute Apgar score. However, the odds ratio for working for a short time during pregnancy changed from 0.69 in Model 1 to 1.28 in Model 2.

\section{Discussion}

Mothers (or other guardians) who consented to take part in the study completed the JECS questionnaire. The current study used data from approximately 100,000 expectant mothers to investigate factors related to whether they responded to a survey that they were to complete one month after giving birth. Factors related to survey non-response were the mother's age at delivery, level of education, hours worked per week, and the child's health at birth. Furthermore, survey non-response differed depending on how actively the mother's partner participated in the JECS.

Approximately $45 \%$ of children in 2013 were part of the JECS (the number of live births registered in JECS divided by the number of all live births within the study areas). Nevertheless, the data on the characteristics of the mothers and children we studied showed marked similarity to those obtained from Japan's 2013 Vital Statistics Survey [2].

Previous studies have reported that survey responses may have been affected by participants' health-related behaviors and socioeconomic factors. Several studies have shown that early age, alcohol, smoking, low income, and low educational status were associated with non-response [5,7,13-21]. Nakai et al surveyed health-related behaviors in Japan and showed that there were more elderly people and less current smokers in the early response group [22]. In the non-response group, more individuals were young, currently smoking, exposed to secondary smoke, with low educational levels, and with low income. Alcohol consumption during early pregnancy was associated with a high response rate.One of the objectives of the JECS was to assess environmental factors that affect children's health (e.g., the mother's health factors). Previous research suggested that the salience of thesurvey topic was associated with a prompt response[23].Inthis survey, participants with an interest in the effect of alcohol consumption on children's health were more likely to respond, and participants with long work hours were more likely to respond to the M1m questionnaire. In the Survey on Time Use and Leisure Activities in 2011 [24], women who worked from home (family workers) spent more time on housework and less time on self-education/training and hobbies/amusement than did those employed outside the home.Associationsof time spent answering the questionnaire with responses to the questionnaire were also observed.

This study found that the attitudes of participants' partners toward JECS participation were an important factor. Having a partner who showed active involvement with the JECS- by agreeing to participate in the study and sending in their survey- was significantly predictive of participant response. Conversely, having a partner who showed passive involvement in the study by agreeing to take part but not sending in his survey strongly predicted participant non-response. A meta-analysis of 14 articles suggested that partner cooperation during pregnancy and postpartum could have a positive effect on maternal health [25]. A study of prenatal genetic testing found that husbands and wives shared concerns about the test and its results [26]. Additionally, a survey found that pregnant women who stopped smoking after pregnancy but whose husbands smoked frequently were more likely to resume smoking later on. This suggests that partners influence maternal smoking behavior [27]. These results suggest that the response rate is negatively affected if the individuals surrounding participants are familiar with the research but take part inactively.

Previous studies have shown that poor health when completing a survey may be related to survey non-response [28,29]. According to Fukutomi et al, from 2004-2006, the prevalence of bronchial asthma in Japanese women aged 20-44 years 6 was 10.9\% (10.1-11.8\%). The rate among this study's participants (10.9\%) was the same [30]. In a study of women of reproductive age, Fida and colleagues found that increased weight was related to asthma recurrence [31]. Further, when Ronmark et al followed up on the results of a survey on respiratory health, they found significantly higher rates of wheezing, asthma, and chronic cough among non-responders [32]. The current study's results suggest that in participants with a history of bronchial asthma and chronic cough, pregnancy-related weight gain may relate to survey non-response. In a study among participants from the Australian Longitudinal Birth Cohort Study, Ng et al suggested that mothers who have a higher risk of psychological distress were likely to not respond at a one-year follow-up [33]. In this study, there were more non-respondents to M1m among participants with a higher risk of psychological distress during pregnancy.

Survey response is affected not only by the health of the survey participants themselves but also by the health of their neonates. Given that one of the outcomes included among the JECS hypotheses is the prevalence of physical anomalies in neonates, non-response bias due to neonatal health problems could affect the testing of such hypotheses. However, as the response rate for the survey at one month after childbirth was high, $94.5 \%$, such an effect would be small at the time.

In survey studies, another potential bias may arise when data from returned questionnaires are consistently incomplete. In this study, a second model used multivariate singular value decomposition to impute missing data. Using logistic regression, the values were then examined in relation to survey non-response. The resulting odds ratios showed similar trends. Moreover, the obtained results indicated that we can expect an improvement in the accuracy of estimating significance and measuring odds ratio changes and potentials. The odds ratio of survey non-response changed with family income and time spent working during pregnancy; these factors were unstable across the groups, since those in the response group were much less likely to leave this information out. Both the time spent working and family income had a higher rate of missing data than other factors in both groups. Family income was missing $8.0 \%$ and $67.6 \%$ of the time for response and non-response groups, respectively. As for time spent working, response and non-response groups did not give this information $32.6 \%$ and $76.6 \%$ of the time respectively.

\section{Study Limitations}

This study had three important limitations. First, the dataset used contained no information regarding the distribution and collection of the 
Citation: Kigawa M, Tsuchida A, Ito M, Tanaka T, Hamazaki K, et al. (2020) Characteristics of Postpartum Japanese Mothers Who Were Non-respondents to the Japan Environment and Children's Study. J Pediatr Congenit Dis 6(1): 105. DOI: https://doi.org/10.47275/2379-6707-105

surveys. Second, in Japan, there is a custom of "Satogaeribunben," wherein pregnant women return to their parents' homes for giving birth; this may have made it difficult to reply to the M1m questionnaire. Third, not all the partners of the participants were asked to take part in the JECS.

Previous studies have indicated that survey response rates differ depending on the type of survey [7,34-38]. In the JECS, Research Coordinators usually gave mothers the survey while they were in the hospital for their deliveries. The surveys were answered one month after childbirth, and the completed surveys were collected by research coordinators Research Coordinators when participants visited participating facilities for their onemonth checkup. However, in some cases, the surveys were sent and returned via mail. As this difference was not considered in the dataset used for this analysis, it was not possible to examine how it may have related to non-response. On the other hand, according to the Ministry of Health, Labor, and Welfare (MHLW), about $80 \%$ of neonates received a one-month checkup [39], suggesting that most of the survey data used in this study came from surveys that were distributed and collected by the JECS Research Coordinators.

Questions about Satogaeribunben were not included in the M1m questionnaire; as such; we were unable to determine who were engaging in the practice and did not assess the effect of Satogaeribunben on non-response. However, all M1m questionnaires were delivered to participating women by the Research Coordinators in obstetrics departments participating in the study. As such, the opportunity to return the questionnaires can be considered uniform.

Regarding the final limitation, partners were requested to participate in the JECS by the Research Coordinator when they were interviewed in person. However, when staff members were unable to conduct that interview, those partners were treated as non-participants in the dataset. This would suggest the possibility that partners who may have been interested in JECS were inadvertently included in the non-participant group. This weakens the relationship between active/inactive participation partners and nonparticipation partners. Despite these factors, this study found significant differences in the collected data. Additionally, partners who agreed to participate but had negative thoughts about participation may have been included in the group of inactive participants, which may have delayed the return of questionnaires. The results of this study suggest that such partners (delayed refusals) may have been included in the inactive participation partner group.

\section{Conclusion}

Cross-sectional studies have determined that participant age, socioeconomic status, and interest in the hypothesis are related to survey nonresponse. This study confirmed that the factors associated with non-response to the JCES as a cohort study were similar to those of cross-sectional studies. Additionally, the research participation status of the participants' partners was related to non-response.

\section{Acknowledgements}

We appreciate the children and their families who took part in this study. We also thank the members of the Japan Environment and Children's Study (JECS), as of 2019 (principal investigator, Michihiro Kamijima): Arata Yamazaki (Core Center for JECS), Yukihiro Ohya (Medical Support Center for JECS, National Center for Child Health and Development, Tokyo, Japan), Reiko Kishi (Hokkaido Regional Center for JECS, Hokkaido University, Sapporo, Japan), Nobuo Yaegashi (Miyagi Regional Center for JECS, Tohoku University, Sendai, Japan), Koichi Hashimoto (Fukushima Regional Center for JECS, Fukushima Medical University, Fukushima, Japan), Chisato Mori (Chiba Regional Center for JECS, Chiba University, Chiba, Japan), Shuichi Ito (Kanagawa Regional Center for JECS, Yokohama City University, Yokohama, Japan), Zentaro Yamagata (Koshin Regional Center for JECS, University of Yamanashi, Chuo, Japan), Hidekuni Inadera (Toyama Regional Center for JECS, University of Toyama, Toyama, Japan), Michihiro Kamijima (Aichi Regional Center for JECS, Nagoya City University, Nagoya, Japan), Takeo Nakayama (Kyoto Regional Center for JECS, Kyoto University, Kyoto, Japan), Hiroyasu Iso (Osaka Regional Center for JECS, Osaka University, Suita, Japan), Masayuki Shima (Hyogo Regional Center for JECS, Hyogo College of Medicine, Nishinomiya, Japan), YouichiKurozawa (Tottori Regional Center for JECS, Tottori University, Yonago, Japan), Narufumi Suganuma (Kochi Regional Center for JECS, Kochi University, Nankoku, Japan), Koichi Kusuhara (Fukuoka Regional Center for JECS, University of Occupational and Environmental Health, Kitakyushu, Japan), and Takahiko Katoh (South Kyushu/Okinawa Regional Center for JECS, Kumamoto University, Kumamoto, Japan).

\section{References}

1. Kawamoto T, Nitta H, Murata K, Toda E, Tsukamoto N, et al. 2014. Rationale and study design of the Japan environment and children's study (JECS). BMC Public Health 14(1):25. https://doi.org/10.1186/1471-2458-14-25

2. Michikawa T, Nitta H, Nakayama SF, Yamazaki S, Isobe T, et al. 2018. Baseline profile of participants in the Japan Environment and Children's Study (JECS). J Epidemiol 28(2):99-104. https://doi.org/10.2188/jea.je20170018

3. Inaba, A. Problems relation to declining response rates to social survey research in Japan: Trends after 2000. 2007. Int J Jap Soc 16(1):10-22.https://doi.org/10.1111/j.14756781.2007.00095.x

4. Austin MA, Criqui MH, Barrett-Connor E, Holdbrook MJ. 1981. The effect of response bias on the odds ratio. Am J Epidemiol 114(1):137-143.https://oi.org/10.1093/oxfordjournals. aje.a113160

5. Christensen AI, Ekholm O, Gray L, Glümer C, Juel K. 2015. What is wrong with non-respondents? Alcohol-, drug- and smoking-related mortality and morbidity in a 12-year follow-up study of respondents and non-respondents in the Danish Health and Morbidity Survey. Addiction 110(9):1505-1512.https://doi.org/10.1111/add.12939

6. Korkeila K, Suominen S, Ahvenainen J, Ojanlatva A, Rautava P, et al. 2001. Non-response and related factors in a nation-wide health survey. Eur J Epidemiol 17(11):991-999.https:// doi.org/10.1023/a:1020016922473

7. Pietila AM, Rantakallio P, Laara E. 1995. Background factors predicting non-response in a health survey of northern Finnish young men. Scand J Soc Med 23(2):129-136.https://doi. org/10.1177/140349489502300208

8. Schneider KL, Clark MA, Rakowski W, Lapane KL. 2012. Evaluating the impact of non-response bias in the Behavioral Risk Factor Surveillance System (BRFSS). J Epidemiol Community Health 66(4):290-295.https://doi.org/10.1136/jech.2009.103861 
Citation: Kigawa M, Tsuchida A, Ito M, Tanaka T, Hamazaki K, et al. (2020) Characteristics of Postpartum Japanese Mothers Who Were Non-respondents to the Japan Environment and Children's Study. J Pediatr Congenit Dis 6(1): 105. DOI: https://doi.org/10.47275/2379-6707-105.

9. Stang A. 2003. Non-response research: an underdeveloped field in epidemiology. Eur J Epidemiol 18(10):929-932.https://doi.org/10.1023/a:1025877501423

10. Young AF, Powers JR, Bell SL. 2006. Attrition in longitudinal studies: who do you lose? Aust N Z J Public Health 30(4):353-361.https://doi.org/10.1111/j.1467-842x.2006.tb00849.x

11. Fukuhara S, Suzukamo Y. 2004. Manual of the SF-8 Japanese Version. Kyoto. Institute for Health Outcome and Process Evaluation Research.

12. Furukawa TA, Kawakami N, Saitoh M, Ono Y, Nakane Y, et al. 2008. The performance of the Japanese version of the K6 and K10 in the World Mental Health Survey Japan. Int $J$ Methods Psychiatr Res 17(3):152-158.https://doi.org/10.1002/mpr.257

13. Abrahamsen R, Svendsen MV, Henneberger PK, Gundersen GF, Torén K, et al. 2016. Non-response in a cross-sectional study of respiratory health in Norway. BMJ Open 6(1): e09912. https://doi.org/10.1136/bmjopen-2015-009912

14. Barchielli A, Balzi D. 2002. Nine-year follow-up of a survey on smoking habits in Florence (Italy): higher mortality among non-responders. Int J Epidemiol 31(5):1038-1042.https:// doi.org/10.1093/ije/31.5.1038

15. Jacobsen TN, Nohr EA, Frydenberg M. 2010. Selection by socioeconomic factors into the Danish National Birth Cohort. Eur J Epidemiol 25(5):349-355.https://doi.org/10.1007/s10654$010-9448-2$

16. Van Loon AJM, Tijhuis M, Picavet HSJ, Surtees PG, Ormel J. 2003. Survey non-response in the Netherlands: effects on prevalence estimates and associations. Ann Epidemiol 13(2):105110.https://doi.org/10.1016/s1047-2797(02)00257-0

17. Macera CA, Jackson KL, Davis DR, Kronenfeld JJ, Blair SN. 1990. Patterns of non-response to a mail survey. J Clin Epidemiol 43(12):1427-1430.https://doi.org/10.1016/08954356(90)90112-3

18. Madigan MP, Troisi R, Potischman N, Brogan D, Gammon MD, et al. 2000. Characteristics of respondents and non-respondents from a case-control study of breast cancer in younger women. Int J Epidemiol 29(5):793-798.https://doi.org/10.1093/ije/29.5.793

19. Nakai S, Hashimoto S, Murakami Y, Hayashi M, Manabe K, et al. 1997. Response rates and non-response bias in a health-related mailed survey. Nihon Koshu Eisei Zasshi 44(3):184191.

20. Nieminen T, Prattala R, Martelin T, Harkanen T, Hyyppa MT, et al. 2013. Social capital, health behaviours and health: a population-based associational study. BMC Public Health 13:613. https://doi.org/10.1186/1471-2458-13-613

21. Tolonen H, Laatikainen T, Helakorpi S, Talala K, Martelin T, et al. 2009. Marital status, educational level and household income explain part of the excess mortality of survey nonrespondents. Eur J Epidemiol 25(2):69-76.https://doi.org/10.1007/s10654-009-9389-9

22. Nakai S, Hashimoto S, Murakami Y, Hayashi M, Manabe K, et al. 1997. Response rates and non-response bias in a health-related mailed survey.Japanese journal of public health 44(3):184-191.

23. Leadbetter S, Hawkins NA, Scholl LE, McCarty FA, Rodriguez JL, et al. 2013. Recruiting women for astudy on perceived risk of cancer: influence of survey topic salienceand early versus late response. Prev Chronic Dis 10:E75.https://doi.org/10.5888/pcd10.120293

24. 2013. Statistics Bureau, Ministry of Internal Affairs. Survey on time use andleisure activities.

25. Yargawa J, Leonardi-Bee J. 2015. Male involvement and maternal health outcomes: systematic review and meta-analysis. J Epidemiol Community Health 69(6): 604-612.https://doi. org/10.1136/jech-2014-204784

26. Finley SC, Varner PD, Vinson PC, Finley WH. 1977. Participants' reaction to amniocentesis and prenatal genetic studies. JAMA 238(22): 2377-2379.https://doi.org/10.1001/ jama.1977.03280230041018

27. Inazu N, Kyokuyama S, Kato S, Kurosaki H, Kumagai M, et al. 2008. Changes in smoking and nonsmoking of perinatal women, and their factors on them (in Japanese). Bulletin of Teikyo Heisei Nursing Junior College 18: 21-26.

28. Dengler R, Roberts H, Rushton L. 1997. Lifestyle surveys--the complete answer? J Epidemiol Community Health 51(1):46-51.https://doi.org/10.1136/jech.51.1.46

29. Etter JF, Perneger TV. 1997. Analysis of non-response bias in a mailed health survey. J Clin Epidemiol 50(10):1123-1128.https://doi.org/10.1016/s0895-4356(97)00166-2

30. Fukutomi Y, Nakamura H, Kobayashi F, Taniguchi M, Konno S, et al. 2010. Nationwide cross-sectional population-based study on the prevalences of asthma and asthma symptoms among Japanese adults. Int Arch Allergy Immunol 153(3):280-287.https://doi.org/10.1159/000314369

31. Fida NG, Enquobahrie DA, Gelaye B, Qiu C, Williams MA. 2011. Associations of asthma with body mass index and adult weight change among reproductive age women. $J$ Asthma 48(7):701-706.https://doi.org/10.3109/02770903.2011.604885

32. Ronmark E, Lundqvist A, Lundback B, Nystrom L. 1999. Non-responders to a postal questionnaire on respiratory symptoms and diseases. Eur J Epidemiol 15(3):293-299.https://doi. org/10.1023/a:1007582518922

33. Ng S-K, Scott R, Scuffham PA. 2016. Contactable non-responders show different characteristics compared to lost to follow-up participants: Insights from an Australian longitudinal birth cohort study. Matern Child Health J 20(7):1472-1484.https://doi.org/10.1007/s10995-016-1946-8

34. Corry NH, Williams CS, Battaglia M, McMaster HS, Stander VA. 2017. Assessing and adjusting for non-response in the Millennium Cohort Family Study. BMC Med Res Methodol 17(1):16.https://doi.org/10.1186/s12874-017-0294-8

35. Christensen AI, Ekholm O, Glumer C, Juel K. 2014. Effect of survey mode on response patterns: comparison of face-to-face and self-administered modes in health surveys. Eur J Public Health 24(2):327-332.https://doi.org/10.1093/eurpub/ckt067

36. Mindell JS, Tipping S, Pickering K, Hope S, Roth MA, et al. 2010. The effect of survey method on survey participation: analysis of data from the Health Survey for England 2006 and the Boost Survey for London. BMC Med Res Methodol 10(1):83.https://doi.org/10.1186/1471-2288-10-83

37. Parr CL, Hjartaker A, Scheel I, Lund E, Laake P, et al. 2008. Comparing methods for handling missing values in food-frequency questionnaires and proposing k nearest neighbours imputation: effects on dietary intake in the Norwegian Women and Cancer study (NOWAC). Public Health Nutr 11(4):361-370.https://doi.org/10.1017/s1368980007000365

38. Johnson S, Seaton SE, Manktelow BN, Smith LK, Field D, et al. 2014. Telephone interviews and online questionnaires can be used to improve neurodevelopmental follow-up rates. BMC Res Notes 7(1):219.https://doi.org/10.1186/1756-0500-7-219

39. 2017. Ministry of Health Law: Report on Regional Public Health Services and Health Promotion Services. 